Article

\title{
Kale Extract Increases Glutathione Levels in V79 Cells, but Does not Protect Them Against Acute Toxicity Induced by Hydrogen Peroxide
}

Fátima Fernandes ${ }^{1}$, Carla Sousa ${ }^{1}$, Federico Ferreres ${ }^{2}$, Patrícia Valentão ${ }^{1}$, Fernando Remião ${ }^{3}$, José A. Pereira ${ }^{4}$ and Paula B. Andrade ${ }^{1, *}$

1 REQUIMTE/Laboratório de Farmacognosia, Departamento de Química, Faculdade de Farmácia, Universidade do Porto, Rua de Jorge Viterbo Ferreira, nº 228, 4050-313 Porto, Portugal;

E-Mails: mfgfernandes@gmail.com (F.F.); csousa@ff.up.pt (C.S.); valentao@ff.up.pt (P.V.)

2 Research Group on Quality, Safety and Bioactivity of Plant Foods, Department of Food Science and Technology, CEBAS (CSIC), P.O. Box 164, Campus University Espinardo, Murcia 30100, Spain; E-Mail: federico@cebas.csic.es

3 REQUIMTE/Laboratório de Toxicologia, Departamento de Ciências Biológicas, Faculdade de Farmácia, Universidade do Porto, Rua de Jorge Viterbo Ferreira, $n^{\circ} 228$, 4050-313 Porto, Portugal; E-Mail: remiao@ff.up.pt

4 CIMO/Escola de Agricultura, Instituto Politécnico de Bragança, Campus Sta Apolónia, Apt. 1171, 5301-854 Bragança, Portugal; E-Mail: jpereira@ipb.pt

* Author to whom correspondence should be addressed; E-Mail: pandrade@ff.up.pt; Tel.: +351-22-0428-654; Fax: +351-22-6093-390.

Received: 9 April 2012; in revised form: 24 April 2012 / Accepted: 25 April 2012 / Published: 7 May 2012

Abstract: This study aims to evaluate the antioxidant potential of extracts of Brassica oleracea L. var. acephala DC. (kale) and several materials of Pieris brassicae L., a common pest of Brassica cultures using a cellular model with hamster lung fibroblast (V79 cells) under quiescent conditions and subjected to $\mathrm{H}_{2} \mathrm{O}_{2}$-induced oxidative stress. Cytotoxicity was evaluated by 3-(4,5-dimethylthiazol-2-yl)-2,5-diphenyl tetrazolium bromide (MTT) assay and glutathione was determined by the 5,5'-dithiobis(2-nitrobenzoic acid) (DTNB)-oxidized glutathione (GSSG) reductase recycling assay. The phenolic composition of the extracts was also established by HPLC-DAD. They presented acylated and non acylated flavonoid glycosides, some of them sulfated, and hydroxycinnamic acyl gentiobiosides. All extracts were cytotoxic by themselves at high concentrations and failed to protect V79 cells against $\mathrm{H}_{2} \mathrm{O}_{2}$ acute toxicity. No relationship between phenolic 
composition and cytotoxicity of the extracts was found. Rather, a significant increase in glutathione was observed in cells exposed to kale extract, which contained the highest amount and variety of flavonoids. It can be concluded that although flavonoids-rich extracts have the ability to increase cellular antioxidant defenses, the use of extracts of kale and $P$. brassicae materials by pharmaceutical or food industries, may constitute an insult to health, especially to debilitated individuals, if high doses are consumed.

Keywords: Brassica oleracea var. acephala; Pieris brassicae; phenolic compounds; V79 cells; oxidative stress; glutathione status

\section{Introduction}

Several epidemiological studies have indicated that regular consumption of Brassica vegetables is strongly associated with a reduced risk of developing certain cancers [1]. In general, the consumption of fruits and vegetables can bring beneficial health effects due to the presence of a wide array of phytochemicals. Phenolic compounds are claimed to possess antioxidant properties and therefore can help in the prevention of chronic diseases, such as atherosclerosis, diabetes, cardiovascular diseases and ischemia and of neurodegenerative disorders like Alzheimer's and Parkinson's [2,3].

In fact, studies using cell cultures demonstrated that flavonoids like kaempferol, quercetin and their glycosides have antioxidant activity. In contrast to their antioxidant activity, phenolics also have the potential to act as pro-oxidants under certain conditions. The pro-oxidant properties of flavonoids and other polyphenols could contribute to tumor cell apoptosis and cancer chemoprevention induced by oxidant species [4].

Brassica oleracea L. varieties, namely kale (Brassica oleracea L. var. acephala DC.), have been intensively studied and are an important dietary source of bioactive compounds, including glucosinolates and phenolics, like flavonols and hydroxycinnamic acid derivatives [5-7].

The study of the role of several classes of compounds in shaping insect-plant relationships has known a great impulse over the last few years. Our group described the role of phenolic compounds in the modulation of the feeding behavior of herbivore organisms, such as Pieris brassicae L. (Lepidoptera: Pieridae), a common pest of Brassica cultures. This insect revealed ability to sequester, metabolize and excrete phenolics obtained from distinct host plants [6,8-12]. Furthermore, the extracts of P. brassicae materials (butterfly, larvae and its excrements) reared on kale proved to have a better antioxidant potential than host plant, depending on the radical species, in cell free systems [6]. As so, $P$. brassicae may have interest as a source of antioxidants.

It is known that the antioxidant activity of a given matrix is dependent on the test system used [13]. Extracts that reveal high antioxidant potential in cell free systems can be either protective or toxic in cellular assays, depending on the extract concentration and cellular conditions [14,15]. So, this work intended to characterize the antioxidant capacity of kale and materials of $P$. brassicae (Figure 1) reared on this plant in hamster lung fibroblast (V79 cells) subjected to hydrogen peroxide $\left(\mathrm{H}_{2} \mathrm{O}_{2}\right)$-induced oxidative stress. To assess the effects in V79 cells under quiescent conditions and exposed to $\mathrm{H}_{2} \mathrm{O}_{2}$, cellular viability and glutathione (GSH) status were evaluated by the 3-(4,5-dimethylthiazol-2-yl)-2,5- 
diphenyl tetrazolium bromide (MTT) reduction assay and 5,5'-dithiobis(2-nitrobenzoic acid) (DTNB)-oxidized glutathione (GSSG) reductase recycling assay, respectively. Additionally, phenolic composition of the extracts was determined by high performance liquid chromatography with diode-array detection (HPLC-DAD) in order to establish possible relations with the cellular effects.

Figure 1. Kale and P. brassicae materials used in this study.

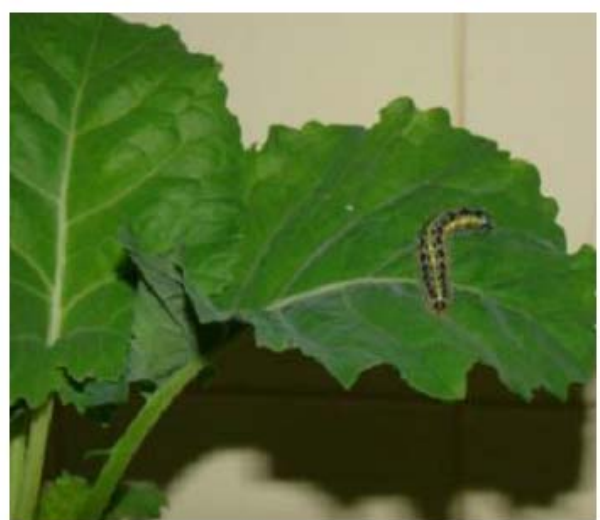

Kale and $P$. brassicae larvae

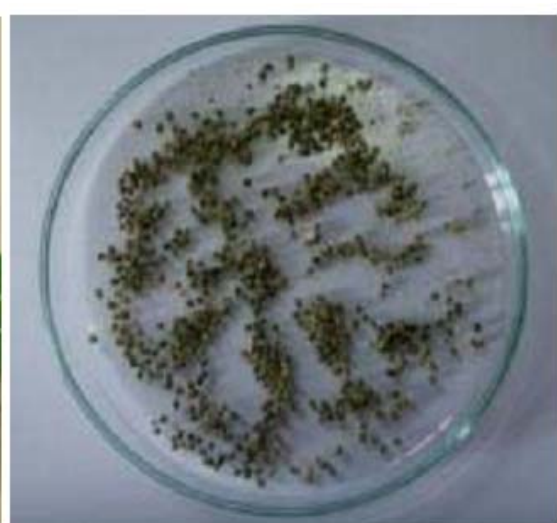

Larvae excrements

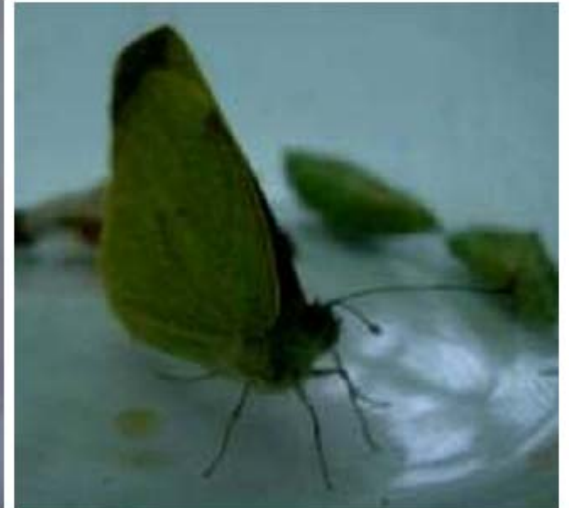

P. brassicae butterfly

2. Results

\subsection{Chemical Composition}

\subsubsection{HPLC-DAD Phenolic Compounds Qualitative Analysis}

In order to characterize the methanolic extracts of kale and of $P$. brassicae butterflies, larvae and its excrements, phenolic compounds were identified by HPLC-DAD. The extracts from kale (Figure 2), P. brassicae larvae (Figure 3A) and their excrements (Figure 3B) contained four groups of phenolic compounds: non acylated flavonoid glycosides (compounds 1, 2, 4, 5, 8, 9, 18-20, 23, 26, 32-35, 37, 39, 41-44), flavonoid glycosides acylated with hydroxycinnamic acids $(3,6,7,10-17,21,22,24,25$, 27, 36, 38, 40, 45 and 46), hydroxycinnamic acyl gentiobiosides (28-31) and free hydroxycinnamic acids (FA and SA).

In the methanolic extract of kale leaves sixteen kaempferol derivatives, nine quercetin derivatives, two isorhamnetin glycosides and four phenolic acids heterosides were found (Figure 2). The phenolic profile of $P$. brassicae larvae was composed by six compounds, including free ferulic and sinapic acids (FA and SA, respectively), two non acylated flavonoid glycosides $(\mathbf{2 3}, \mathbf{2 6})$ and two sulfate derivatives of non acylated flavonoid glycosides $(\mathbf{3 2}, \mathbf{3 3})$ (Figure 3A). Concerning $P$. brassicae excrements, six non-acylated glycosyl flavonols $(2,5,8,19,23$ and 26) were detected (Figure 3B). Other non acylated glycosides present in excrements, and not detected in kale leaves, were kaempferol (32-35, 37, 42 and 43), quercetin (41) and isorhamnetin (39 and 44) derivatives (Table 1). In addition, as it happened with the larvae methanolic extract, flavonol sulfated derivatives were also noted (32, 33 and 41) (Figure 3B, Table 1). No phenolic compound was characterized in P. brassicae butterfly methanolic extract. 
Figure 2. HPLC-DAD phenolic profile of the methanolic extract of $B$. oleracea var. acephala leaves. Detection at $330 \mathrm{~nm}$. Peaks: (1) quercetin-3-O-sophorotrioside-7-Oglucoside, (2) quercetin-3- $O$-sophoroside-7- $O$-glucoside, (3) kaempferol-3- $O$-(methoxycaffeoyl)sophoroside-7- $O$-glucoside, (4) quercetin-3- $O$-sophoroside-7- $O$-diglucoside, (5) kaempferol-3-O-sophoroside-7-O-glucoside, (6) kaempferol-3-O-(caffeoyl)sophoroside-7$O$-glucoside, (7) quercetin-3-O-(sinapoyl)sophoroside-7- $O$-glucoside, (8) kaempferol-3-Osophoroside-7- $O$-diglucoside, (9) isorhamnetin-3- $O$-sophoroside-7- $O$-glucoside, quercetin-3-O-(feruloyl)sophoroside-7-O-glucoside, (11) quercetin-3-O-(feruloyl)sophoroside-7- $O$-diglucoside, (12) kaempferol-3- $O$-(sinapoyl)sophoroside-7- $O$-glucoside, (13) kaempferol-3-O-(sinapoyl)sophoroside-7-O-diglucoside, (14) kaempferol-3-O(feruloyl)sophoroside-7- $O$-glucoside, (15) kaempferol-3-O-(feruloyl)sophoroside-7-Odiglucoside, (16) kaempferol-3-O-( $p$-coumaroyl)sophoroside-7-O-glucoside, kaempferol-3-O-( $p$-coumaroyl)sophoroside-7- $O$-diglucoside, (18) kaempferol-3- $O$-gentiobioside-7-O-glucoside, (19) kaempferol-3- $O$-gentiobioside-7- $O$-diglucoside, isorhamnetin-3-O-gentiobioside-7-O-glucoside, (21) quercetin-3-O-(sinapoyl)sophoroside, (22) quercetin-3-O-(feruloyl)sophoroside, (23) quercetin-3-O-sophoroside, kaempferol-3-O-( $p$-coumaroyl)gentiobioside-7-O-glucoside, (25) kaempferol-3-O(sinapoyl)sophoroside, (26) kaempferol-3-O-sophoroside, (27) kaempferol-3-O-(feruloyl)sophoroside, (28) disinapoyl-gentiobioside, (29) sinapoyl,feruloyl-gentiobioside, (30) diferuloyl-gentiobioside, (31) disinapoyl,feruloyl-gentiobioside.

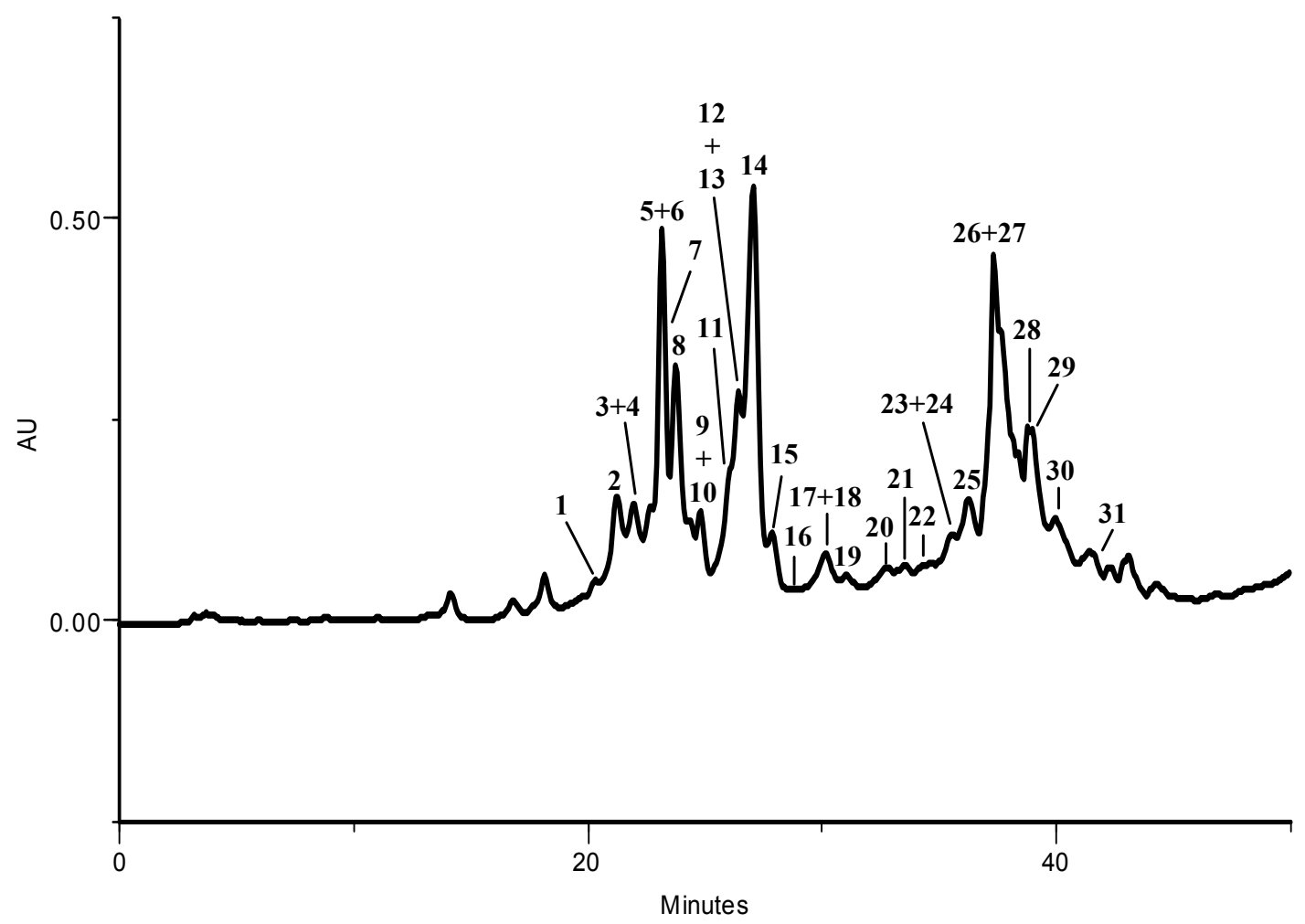


Figure 3. HPLC-DAD phenolic profiles of $P$. brassicae larvae (A) and excrement (B) methanolic extracts. Detection at $330 \mathrm{~nm}$. Peaks: 2, 5, 8, 12-15, 19, 23 and 26 see Figure 2. (FA) Ferulic acid, (SA) sinapic acid, (32) kaempferol-3- $O$-sophoroside sulfate, (33) kaempferol-3-O-glucoside sulfate, (34) kaempferol-3- $O$-sophorotrioside-7-O-glucoside, (35) kaempferol-3- $O$-sophorotrioside-7- $O$-diglucoside; (36) kaempferol-3-O(sinapoyl)sophorotrioside, (37) kaempferol-3- $O$-sophorotrioside, (38) kaempferol-3-O(feruloyl)sophorotrioside, (39) isorhamnetin-3- $O$-sophoroside, (40) kaempferol-3- $O$ - $(p$ coumaroyl)sophorotrioside, (41) quercetin-3-O-glucoside sulfate, (42) kaempferol-3-Ogentiobioside, (43) kaempferol-3- $O$-glucoside, (44) isorhamnetin-3- $O$-gentiobioside, (45) kaempferol-3-O-(feruloyl)sophoroside, (46) kaempferol-3-O-(p-coumaroyl)sophoroside.
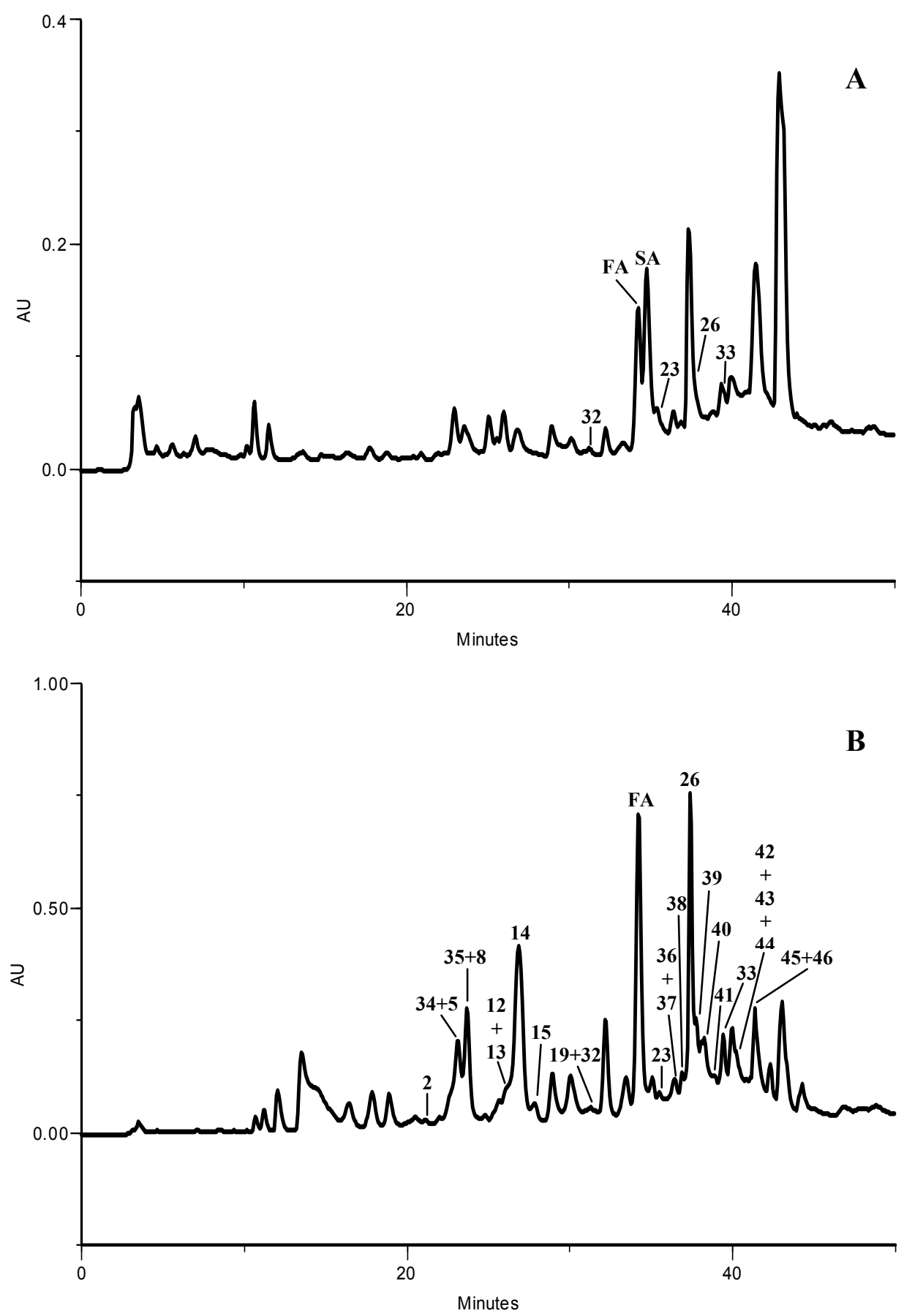
Table 1. Quantification of phenolic compounds in methanolic extracts of B. oleracea var. acephala and $P$. brassicae materials (mg/kg, dry basis) ${ }^{\mathrm{a}}$.

\begin{tabular}{|c|c|c|c|c|}
\hline & Compound & Kale & Larvae & Excrements \\
\hline 1 & Quercetin-3-O-sophtr-7-O-gluc & $12.0(0.1)$ & - & - \\
\hline 2 & Quercetin-3-O-soph-7-O-gluc & $24.3(1.0)$ & - & nq \\
\hline 3 & Kaempferol-3-O-(methoxycaffeoyl)soph-7-O-gluc + & $244.1(15.5)$ & - & - \\
\hline 4 & Quercetin-3-O-soph-7-O-digluc & & - & - \\
\hline 34 & Kaempferol-3-O-sophtr-7-O-gluc + & - & - & $1.4(0.0)$ \\
\hline 5 & Kaempferol-3-O-soph-7-O-gluc + & $310.9(0.1)$ & - & \\
\hline 6 & Kaempferol-3-O-(caffeoyl)soph-7-O-gluc + & & - & - \\
\hline 7 & Quercetin-3-O-(sinapoyl)soph-7-O-gluc & & - & - \\
\hline 35 & Kaempferol-3-O-sophtr-7- $O$-digluc + & - & - & $5.4(0.1)$ \\
\hline 8 & Kaempferol-3-O-soph-7-O-digluc & $75.1(8.2)$ & - & \\
\hline 9 & Isorhamnetin-3-O-soph-7-O-gluc + & $34.8(2.6)$ & - & - \\
\hline 10 & Quercetin-3-O-(feruloyl)soph-7-O-gluc & & - & - \\
\hline 11 & Quercetin-3-O-(feruloyl)soph-7- $O$-soph + & $883.0(97.8)$ & - & - \\
\hline 12 & Kaempferol-3-O-(sinapoyl)soph-7-O-gluc + & & - & $7.9(0.1)$ \\
\hline 13 & Kaempferol-3-O-(sinapoyl)soph-7-O-soph & & - & \\
\hline 14 & Kaempferol-3-O-(feruloyl)soph-7-O-gluc & $581.6(0.7)$ & - & $10.5(0.1)$ \\
\hline 15 & Kaempferol-3-O-(feruloyl)soph-7-O-soph & $70.4(8.8)$ & - & $1.1(0.1)$ \\
\hline 16 & Kaempferol-3-O-( $p$-coumaroyl)soph-7-O-gluc & $\mathrm{nq}$ & - & - \\
\hline 17 & Kaempferol-3-O-(p-coumaroyl)soph-7- $O$-soph + & $159.5(12.3)$ & - & - \\
\hline 18 & Kaempferol-3-O-gent-7-O-gluc & & - & - \\
\hline 19 & Kaempferol-3-O-gent-7-O-digluc + & $29.7(4.7)$ & - & $3.8(0.7)$ \\
\hline 32 & Kaempferol-3-O-digluc sulfate & - & $\mathrm{nq}$ & \\
\hline 20 & Isorhamnetin-3-O-gent-7-O-gluc & $101.6(9.6)$ & - & - \\
\hline 21 & Quercetin-3-O-(sinapoyl)soph & $16.8(0.1)$ & - & - \\
\hline 22 & Quercetin-3-O-(feruloyl)soph & $16.3(3.6)$ & - & - \\
\hline FA & Ferulic acid & - & $8.3(0.9)$ & $3.0(0.0)$ \\
\hline 23 & Quercetin-3-O-soph + & $31.4(0.9)$ & $16.4(0.8)$ & $1.1(0.0)$ \\
\hline 24 & Kaempferol-3-O-(p-coumaroyl)gent-7-O-gluc & & - & - \\
\hline SA & Sinapic acid & - & $191.0(18.1)$ & - \\
\hline 25 & Kaempferol-3-O-(sinapoyl)soph & $133.5(0.9)$ & - & - \\
\hline 26 & Kaempferol-3-O-soph + & $960.8(35.4)$ & $55.8(1.9)$ & $2.6(0.2)$ \\
\hline 27 & Kaempferol-3-O-(feruloyl)soph & & - & - \\
\hline 28 & Disinapoyl-gent + & $92.2(6.3)$ & - & - \\
\hline 29 & Sinapoyl,feruloyl-gent & & - & - \\
\hline 30 & Diferuloyl-gent & $1.6(0.1)$ & - & - \\
\hline 31 & Disinapoyl,feruloyl-gent & $\mathrm{nq}$ & - & - \\
\hline 33 & Kaempferol-3-O-gluc sulfate & - & $\mathrm{nq}$ & $3.0(0.0)$ \\
\hline 36 & Kaempferol-3-O-(sinapoyl)sophtr + & - & - & $1.2(0.3)$ \\
\hline 37 & Kaempferol-3-O-sophtr & - & - & \\
\hline 38 & Kaempferol-3-O-(feruloyl)sophtr & - & - & $2.4(0.1)$ \\
\hline 39 & Isorhamnetin-3-O-soph & - & - & $0.3(0.0)$ \\
\hline 40 & Kaempferol-3-O-(p-coumaroyl)sophtr & - & - & $0.1(0.0)$ \\
\hline 41 & Quercetin-3-O-gluc sulfate & - & - & $\mathrm{nq}$ \\
\hline 42 & Kaempferol-3-O-gent & - & - & $\mathrm{nq}$ \\
\hline 43 & Kaempferol-3-O-gluc & - & - & $\mathrm{nq}$ \\
\hline 44 & Isorhamnetin-3-O-gent & - & - & \\
\hline 45 & Kaempferol-3-O-(feruloyl)soph + & - & - & $5.5(0.3)$ \\
\hline \multirow[t]{2}{*}{46} & Kaempferol-3-O-(p-coumaroyl)soph & - & - & \\
\hline & $\Sigma$ & 3779.6 & 271.5 & 49.3 \\
\hline
\end{tabular}

${ }^{\mathrm{a}}$ Results are expressed as mean (standard deviation) of three determinations; $\sum$, sum of the determined phenolic compounds; nq: not quantified; -: not detected. No result means the compound was quantified with the previous one; sophtr: sophorotriose; soph: sophorose; gluc: glucose; digluc: diglucose; gent: gentiobiose. 


\subsubsection{Phenolic Compounds Quantitative Analysis}

To better characterize the extracts used in cellular assays, the phenolic compounds were also quantified by HPLC-DAD (Table 1). The highest phenolics content was found in kale leaves extract (ca. $3780 \mathrm{mg} / \mathrm{Kg}$ phenolic compounds), followed by $P$. brassicae larvae and their excrements, with 272 and $49 \mathrm{mg} / \mathrm{Kg}$, respectively (Table 1). The pair 26 plus 27, the group 11, 12 plus 13 and compound 14 were the main phenolics in kale, representing ca. $25 \%, 23 \%$ and $15 \%$ of total compounds, respectively (Table 1). Concerning P. brassicae larvae, the main compound was sinapic acid, corresponding to $70 \%$ of total identified compounds. Kaempferol-3-O-sophoroside (compound 26) was the flavonol present at higher levels, representing ca. $21 \%$ of total phenolics (Table 1). In P. brassicae excrement extract, compound 14 and the pair 12 plus 13 were the major ones (ca. 21\% and $16 \%$, respectively) (Table 1). Concerning the different classes of flavonoids, it can be seen that the three analyzed matrices contain similar relative amounts of non acylated flavonoid glycosides, but differ in flavonoid derivatives acylated with hydroxycinnamic acids, which are absent in larvae extracts (Figure 4). With respect to phenolic acids, kale only contains hydroxycinnamic acyl gentiobiosides, while $P$. brassicae materials (larvae and excrements) just present free hydroxycinnamic acids (Figure 4).

Figure 4. Relative content of the different classes of phenolic compounds in methanolic extracts of B. oleracea var. acephala and P. brassicae materials.

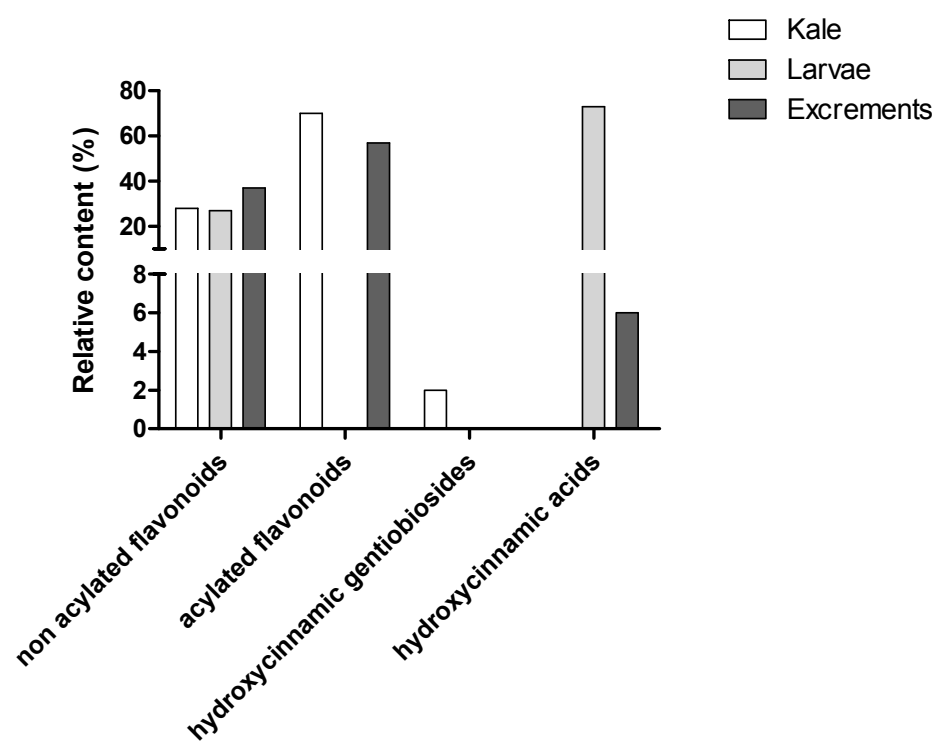

\subsection{Biological Activity}

\subsection{1. $\mathrm{H}_{2} \mathrm{O}_{2}$ Induced Toxicity in V79 Cells}

Cellular viability can be assessed by evaluating mitochondrial function. The mitochondrial dehydrogenases of viable cells, in contrast to dead cells, cleave the tetrazolium ring of the yellow MTT to yield purple formazan [16]. In order to evaluate the potential protective effects of the extracts, V79 cells were exposed to $37.5 \mu \mathrm{M} \mathrm{H}_{2} \mathrm{O}_{2}$ for $30 \mathrm{~min}$, because under these conditions cellular viability was reduced by ca. $50 \%$ (data not shown). 


\subsubsection{Effects of Kale and P. brassicae Extracts on V79 Cells Viability}

The methanolic extracts of kale and $P$. brassicae materials were tested in concentrations equivalent to 0.22 to $135 \mathrm{mg}$ of dried material $/ \mathrm{mL}$. According to the quantification of phenolic compounds (Table 1) this sample concentrations correspond to 0.83 to $510.25 \mu \mathrm{g} / \mathrm{mL}$ of phenolic compounds for kale extracts, 0.06 to $36.65 \mu \mathrm{g} / \mathrm{mL}$ for $P$. brassicae larvae and 0.01 to $6.66 \mu \mathrm{g} / \mathrm{mL}$ for their excrements.

In general, extracts were cytotoxic to V79 cells at the highest concentration tested $(135 \mathrm{mg} / \mathrm{mL}$, $p<0.001$ ) (Figure 5). For this concentration, cellular viability was ca. $46 \%$ for kale, $7 \%$ for larvae and $29 \%$ for butterflies, as ascertained by the results for MTT reduction. P. brassicae larvae and butterfly methanolic extracts already showed a tendency to be toxic to V79 cells at $27 \mathrm{mg} / \mathrm{mL}$ (Figure 5). P. brassicae excrements extract showed MTT reduction higher than $96 \%$ for all concentrations tested.

Figure 5. Effect of $B$. oleracea var. acephala and $P$. brassicae materials methanolic extracts on V79 cells viability with and without $\mathrm{H}_{2} \mathrm{O}_{2}$-induced oxidative stress. Values show mean $\pm \mathrm{SE}(\mathrm{n}=4)$. Mean values were significantly different compared with the respective control $(* p<0.05, * * p<0.01$ and $* * * p<0.001)$.

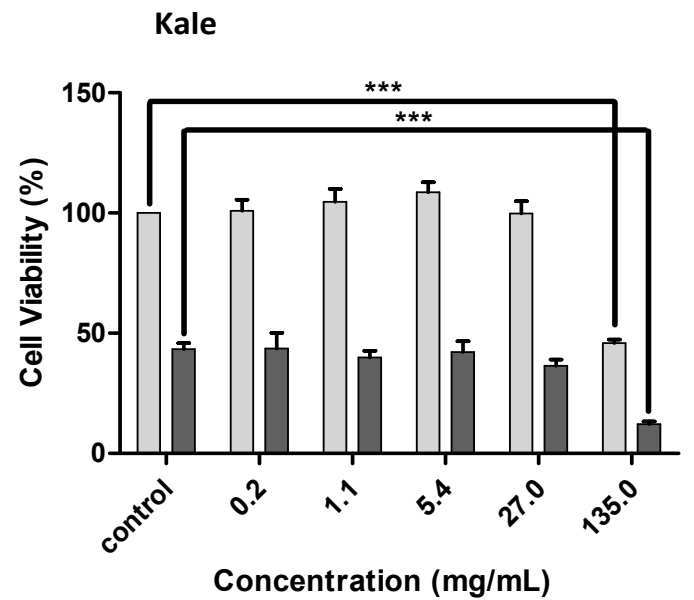

P. brassicae butterfly

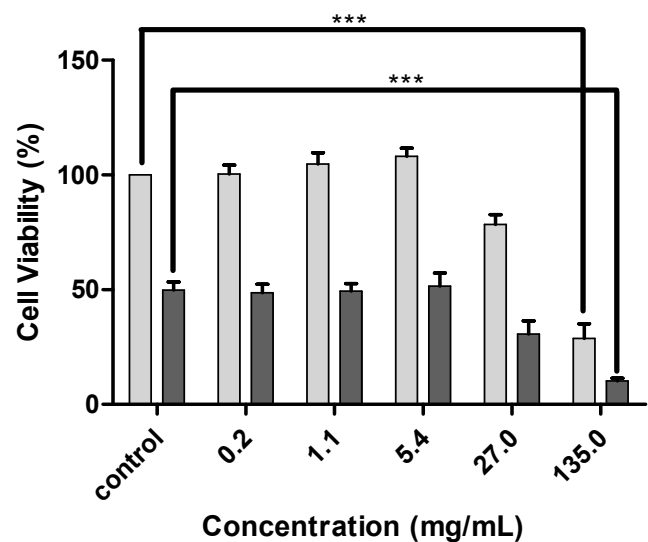

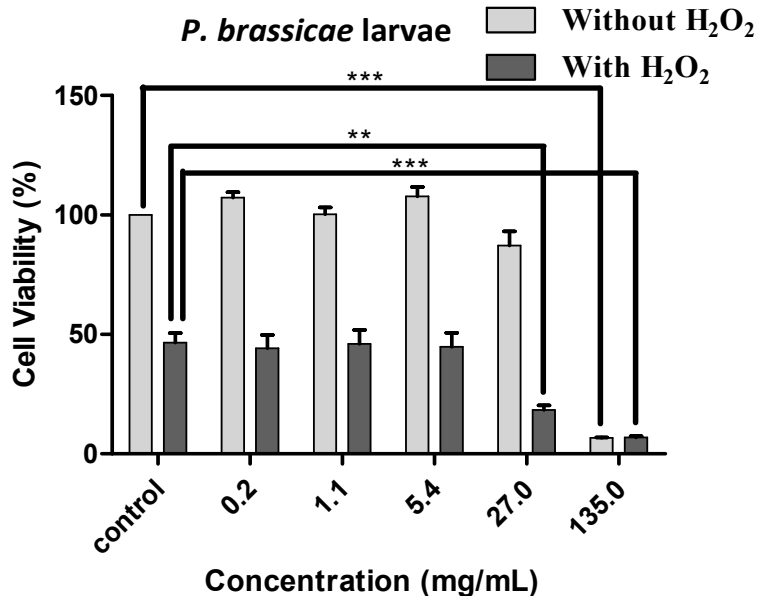

P. brassicae excrements

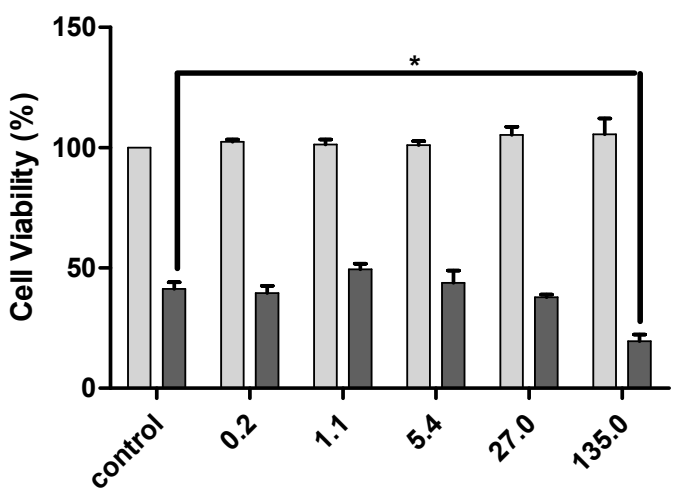

Concentration $(\mathrm{mg} / \mathrm{mL})$

In order to assess the possible role of glycosylated flavonoids, kaempferol-3- $O$-rutinoside, a commercially available flavonoid glycoside closely related to the ones encountered in the extracts, was tested at $1-595 \mu \mathrm{g} / \mathrm{mL}(1.7-1,000 \mu \mathrm{M})$, which correspond to concentrations representative of 
kaempferol derivatives in the extracts (Figure 6). The same was done considering the hydroxycinnamic acids found only in $P$. brassicae larvae and excrements extracts: ferulic acid at $0.042-3.36 \mu \mathrm{g} / \mathrm{mL}$ $(0.2-17.3 \mu \mathrm{M})$ and sinapic acid at $0.32-25.78 \mu \mathrm{g} / \mathrm{mL}(1.4-115.1 \mu \mathrm{M})$ were evaluated. None of the assayed compounds was toxic to V79 cells, as ascertained by the MTT assay (Figure 6).

Figure 6. Effect of kaempferol-3-O-rutinoside, ferulic and sinapic acids on V79 cells viability with and without $\mathrm{H}_{2} \mathrm{O}_{2}$-induced oxidative stress. Values show mean $\pm \mathrm{SE}(\mathrm{n}=4)$.
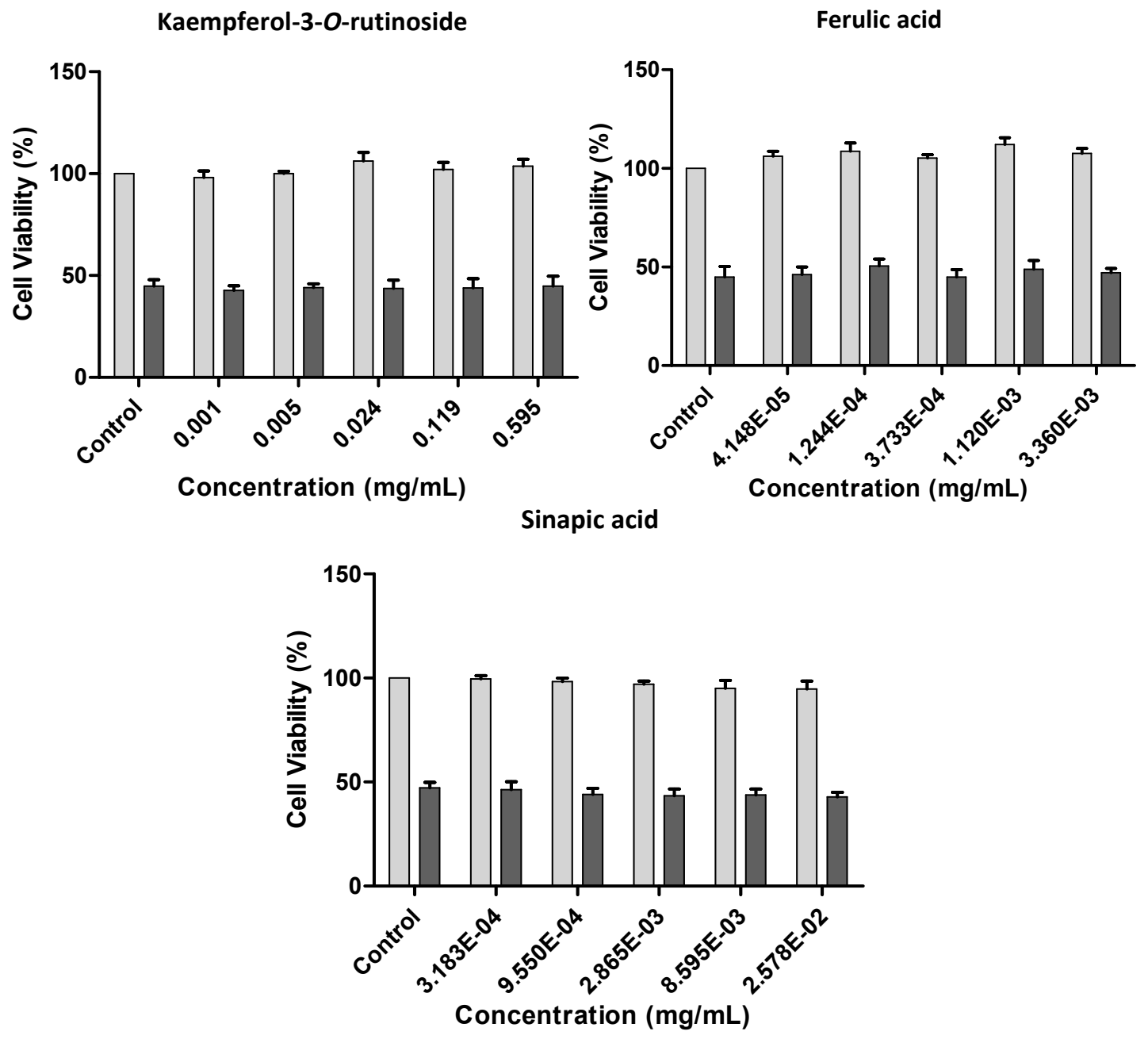

\subsubsection{Effect of Kale and P. brassicae Extracts on Cellular Hydrogen Peroxide-Induced Toxicity}

To evaluate the protective effect of kale and P. brassicae materials, V79 cells were pre-treated with different extract concentrations before exposition to $\mathrm{H}_{2} \mathrm{O}_{2}$. None of the studied extracts provided protection. Furthermore, at the highest tested concentrations the extracts aggravated the toxicity induced by $\mathrm{H}_{2} \mathrm{O}_{2}$ (Figure 5, $p<0.001$ for kale, larvae and butterfly extracts; $p<0.05$ for excrements extracts). The deleterious effects of $P$. brassicae larvae extract were significant at $27.0 \mathrm{mg} / \mathrm{mL}(60 \%$, $p<0.01)$. Kaempferol-3-O-rutinoside, ferulic and sinapic acids, assayed at the concentrations corresponding to their content in the matrices, didn't prevent, nor aggravate the toxicity induced by $\mathrm{H}_{2} \mathrm{O}_{2}$ in V79 cells (Figure 6). 


\subsubsection{Effect of Kale and P. brassicae Extracts on Glutathione Homeostasis}

V79 cells exposed to the methanolic extracts, either in the presence or absence of $\mathrm{H}_{2} \mathrm{O}_{2}$, were evaluated for total glutathione $\left(\mathrm{GSH}_{\mathrm{t}}\right)$ and GSSG contents (Figures 7 and 8).

Figure 7. Effect of $B$. oleracea var. acephala and P. brassicae materials methanolic extracts on GSSG/GSH $\mathrm{t}_{\mathrm{t}}$ of V79 cells, after $24 \mathrm{~h}$ treatment, with and without $\mathrm{H}_{2} \mathrm{O}_{2}$-induced oxidative stress. Values show mean $\pm \mathrm{SE}(\mathrm{n}=4)$. Mean values were significantly different compared with the respective control $(* p<0.05$ and $* * p<0.01)$.
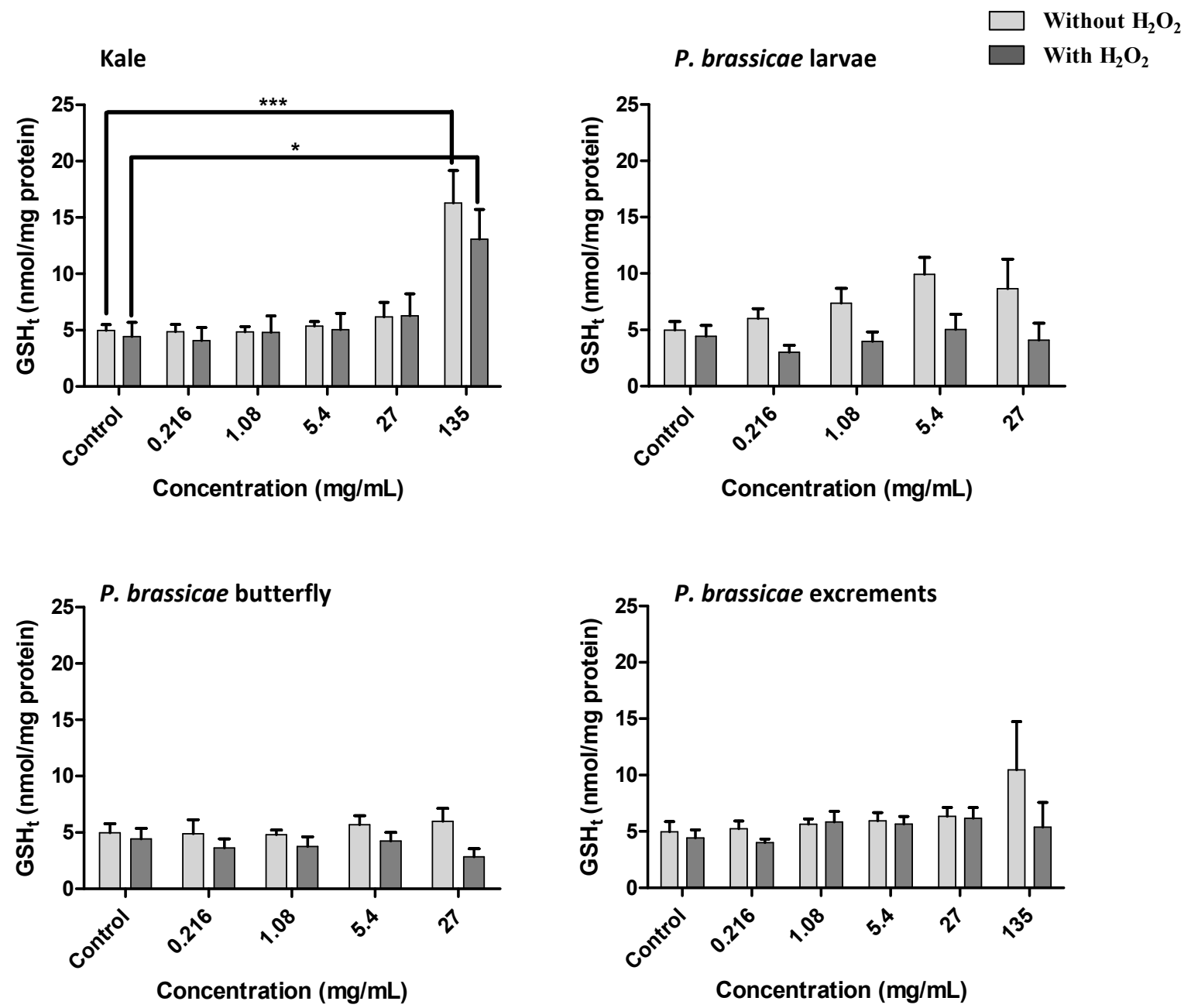

$\mathrm{H}_{2} \mathrm{O}_{2}$ treated cells showed a high $\mathrm{GSSG} / \mathrm{GSH}_{\mathrm{t}}$ ratio compared to quiescent cells (Figure 7). Kale and $P$. brassicae excrements extract lead to a significant disturbance on GSH homeostasis for the highest concentration tested (Figure 7). Comparing with the respective control, the increase in GSSG/GSH $\mathrm{G}_{\mathrm{t}}$ ratio induced by kale extracts was significant in quiescent cells and in cells exposed to $\mathrm{H}_{2} \mathrm{O}_{2}$ (Figure 7, $p<0.05$ ), while for excrements extract this increase was only significant in quiescent cells (Figure 7, $p<0.01$ ). Besides the increase in GSSG/GSH $\mathrm{G}_{\mathrm{t}}$ ratio induced by kale, the $\mathrm{GSH}_{\mathrm{t}}$ levels were also significantly increased by this matrix (Figure $8, p<0.001$ ). This significant effect was also verified after exposition to $\mathrm{H}_{2} \mathrm{O}_{2}$ (Figure $8, p<0.05$ ). 
Figure 8. Effect of $B$. oleracea var. acephala and $P$. brassicae materials methanolic extracts on total glutathione content of V79 cells, after $24 \mathrm{~h}$ treatment, with and without $\mathrm{H}_{2} \mathrm{O}_{2}$-induced oxidative stress. Values show mean $\pm \mathrm{SE}(\mathrm{n}=4)$. Mean values were significantly different compared with the respective control (*p<0.05 and *** $p<0.001)$.

Kale
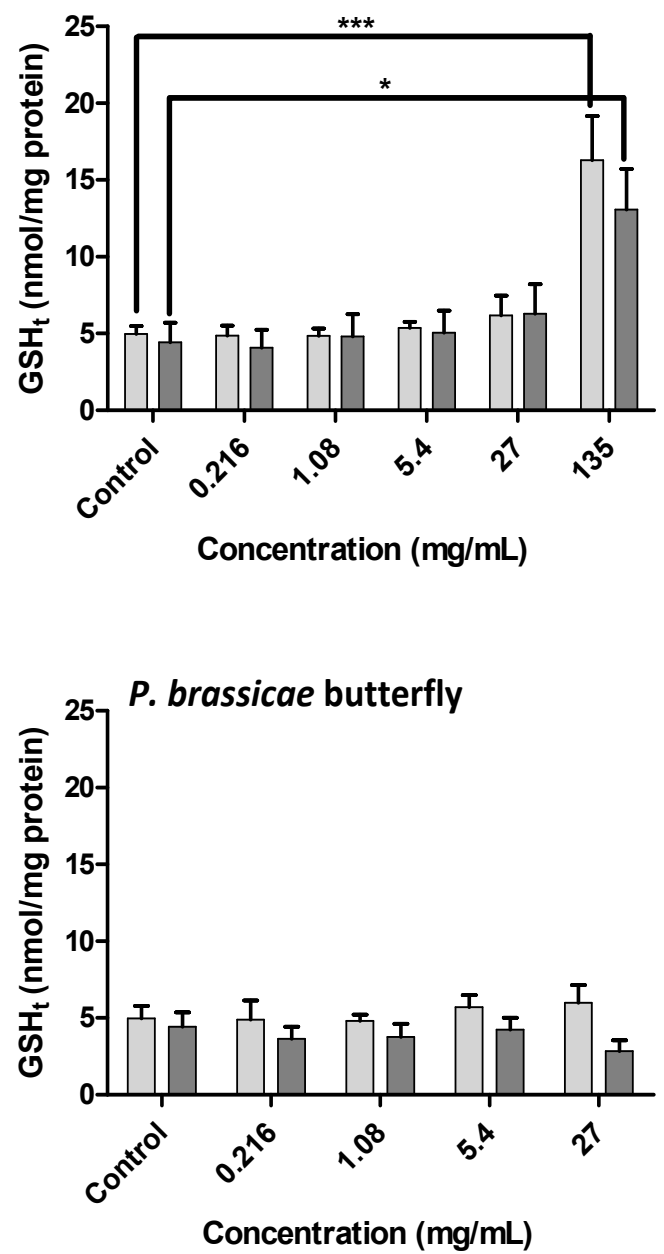

P. brassicae larvae

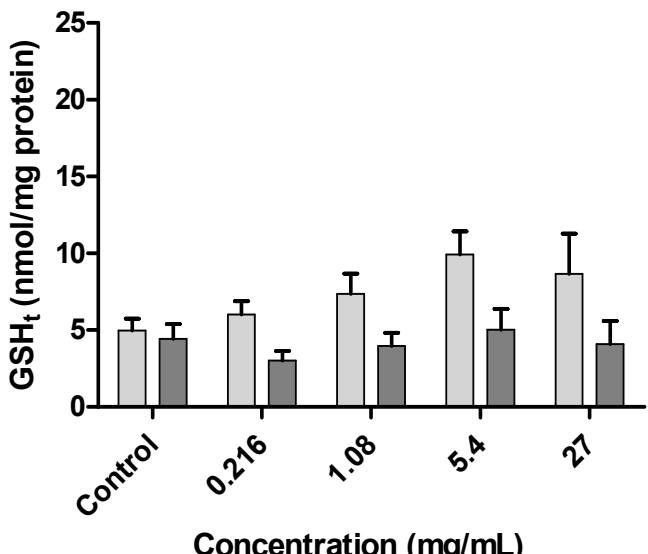

Concentration $(\mathrm{mg} / \mathrm{mL})$

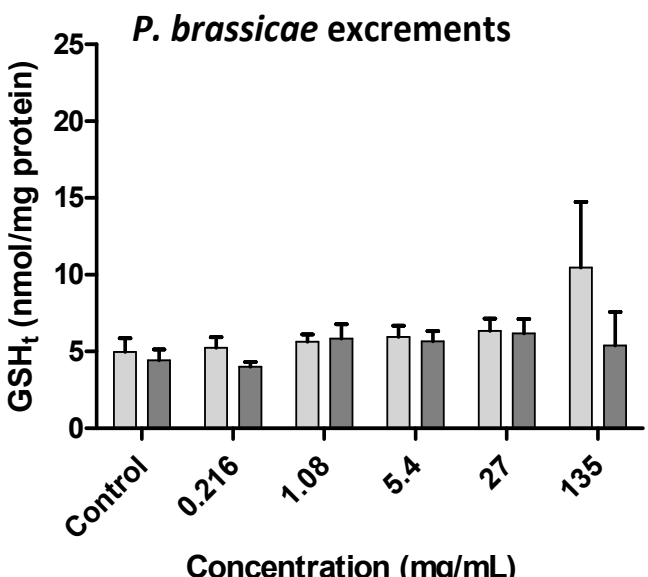

Considering both $P$. brassicae larvae and butterfly extracts, it was not possible to evaluate the glutathione levels at $135 \mathrm{mg} / \mathrm{mL}$, once the cellular viability was already too low at this concentration (Figure 5). The GSSG/GSH $\mathrm{G}_{\mathrm{t}}$ ratio in $\mathrm{V} 79$ cells either with or without $\mathrm{H}_{2} \mathrm{O}_{2}$ treatment was not significantly affected by kaempferol-3-O-rutinoside, sinapic or ferulic acids tested at concentrations corresponding to their contents in the extracts (Figure 9). However, an increase of $\mathrm{GSH}_{\mathrm{t}}$ levels was noticed with the highest tested concentration of kaempferol-3-O-rutinoside $(p<0.05)$, while ferulic and sinapic acids had no effect (Figure 9). 
Figure 9. Effect of kaempferol-3-O-rutinoside, ferulic and sinapic acids on GSSG/GSH and on total glutathione content of V79 cells, after $24 \mathrm{~h}$ treatment, with and without $\mathrm{H}_{2} \mathrm{O}_{2}$-induced oxidative stress. Values show mean $\pm \mathrm{SE}(\mathrm{n}=4)$. Mean values were significantly different compared with the respective control $(* p<0.05)$.

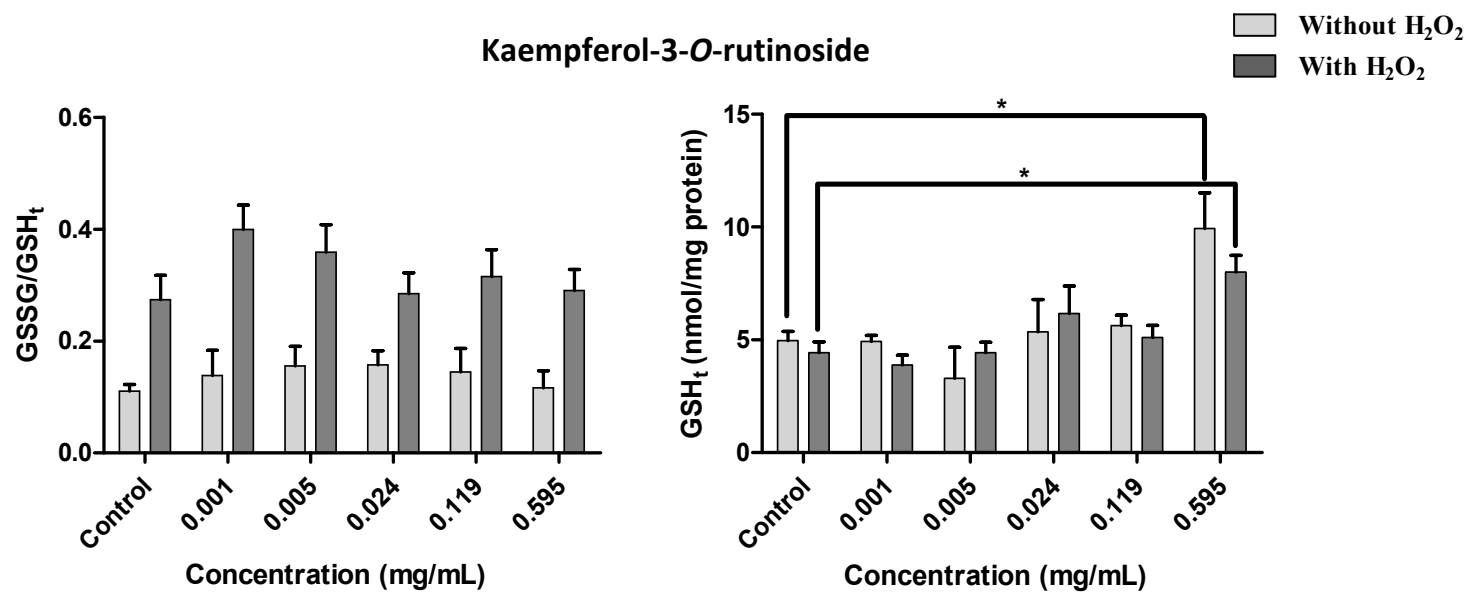

Ferulic acid
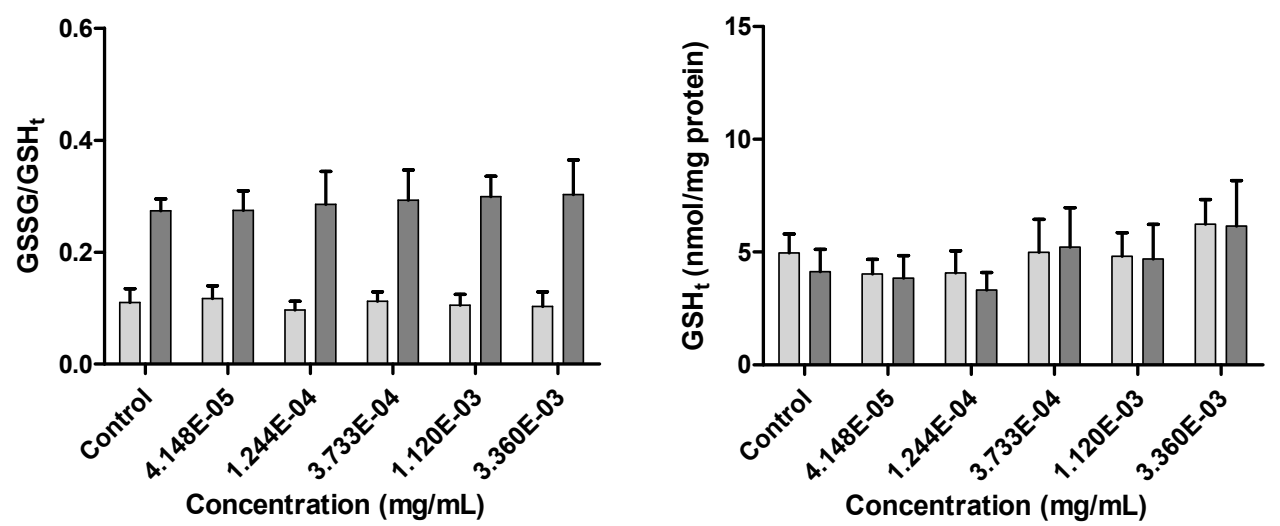

Sinapic acid
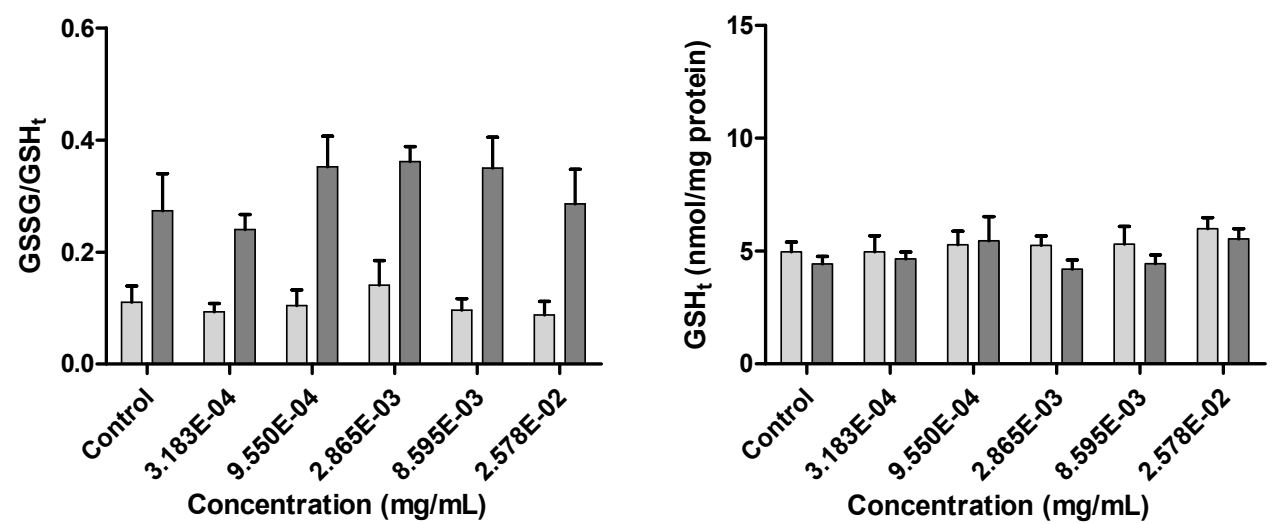

\section{Discussion}

The richness of Brassica plants in phenolic compounds is well documented and it's generally accepted that these secondary metabolites can contribute to the claimed beneficial health effects of vegetables belonging to this genus [2].

Another field of growing interest concerns the potential application of herbivores, that otherwise are considered plagues, as sources of bioactive compounds produced by their host plants. The ability of 
P. brassicae larvae to accumulate, metabolize and excrete phenolic compounds has been thoroughly studied by our group [6,8-12]. The phenolic composition of kale and P. brassicae materials methanolic extracts and their antioxidant potential against acute oxidative stress in a cellular model were now studied.

The HPLC-DAD analysis of the methanolic extracts of kale, $P$. brassicae larvae, excrements and butterflies demonstrates that, in general, the qualitative composition is similar to that of the aqueous extracts of the same materials previously described [6].

The free hydroxycinnamic acids (sinapic and ferulic acids) were not detected in the aqueous extracts previously characterized [6] but were reported before in P. brassicae larvae fed with Brassica rapa var. rapa [9,11] or with B. oleracea var. costata [10]. Their presence in the two referred $P$. brassicae larvae extracts was justified by their occurrence in high content in the host plants, which does not happen in kale. In the $P$. brassicae materials analyzed herein, the hydroxycinnamic acids can result from larvae metabolism, by deacylation of sugars in position 3 of flavonols or from the deglycosylation of hydroxycinnamic acyl gentiobiosides found in kale. Their presence in the methanolic extracts may be due to a more effective extraction by this solvent than by boiling water used in the previous work.

Concerning $P$. brassicae excrement methanolic extract, it contains non acylated glycosides of flavonoids that are not detected in kale leaves (Table 1) and may result from deacylation and other biotransformation reactions of the various acylated flavonol derivatives found in the host plant. In addition, flavonol sulfated derivatives were also noted in the excrements, as well as in the larvae methanolic extract. Conjugation with sulfate is a common phase II detoxification reaction. These compounds are found only in small amounts in P. brassicae larvae, indicating that they are mainly excreted by the insect.

Besides the qualitative differences, the amounts of phenolics varied greatly. The highest phenolics content was found in kale leaves, which contained fourteen times more phenolics than P. brassicae larvae and 77 times more phenolics than the excrements (Table 1).

Although the relative amounts of non acylated flavonoid glycosides were similar among the three studied matrices (kale, larvae and its excrements), the other groups of phenolic compounds greatly differ. The hydroxycinnamic acyl gentiobiosides found in kale are absent in P. brassicae materials, being the opposite true for free hydroxycinnamic acids (Figure 4). Thus, hydrolysis of hydroxycinnamic acyl gentiobiosides by the larvae followed by the accumulation and excretion of the free acid seems to occur. In what concerns to acylated flavonoid glycosides, they seem to be mainly excreted by the larvae, although hydrolysis into the corresponding heteroside and the free hydroxycinnamic acid probably happens, contributing for the total amount of the latter in the larvae.

The antioxidant potential of kale and P. brassicae materials extracts has been previously demonstrated in cell-free systems [6]. However, the promising results obtained in those assays need to be confirmed in biological models more closely related to the in vivo situation.

Lung fibroblasts are reported to respond to oxidative stress [17,18]. Hydrogen peroxide is a physiologic oxidant currently used in the evaluation of the antioxidant potential of phenolic compounds or plant extracts in cellular assays [19-22]. It can easily cross cell membranes, producing deleterious effects within the original or neighboring cells, being regarded as one of the principal intermediaries of cytotoxicity induced by oxidative stress [23]. 
Before being evaluated for their antioxidant potential the extracts were tested in quiescent cells in order to screen for toxic effects. With the exception of $P$. brassicae excrements, the extracts demonstrated to be toxic in concentrations corresponding to $135 \mathrm{mg}$ of dried material $/ \mathrm{mL}$ (Figure 5). Due to the chemical complexity of the extracts, it is not easy to point to which compounds are responsible for the displayed toxicity. However, in order to assess the possible role of phenolic compounds in the displayed toxicity kaempferol-3-O-rutinoside, and ferulic and sinapic acids were tested in the concentration range found in the extracts (Figure 6). It should be noticed that only the lowest concentrations of each tested compound is generally achieved in blood after consumption of polyphenolic rich foods (physiologic concentration about 0.1-1 $\mu \mathrm{M}$ ) [24]. However, the consumption of polyphenolic enriched foods or supplements provide more phenolic compounds than that attained by a typical diet [25]. No toxic effects on V79 cells were observed with these compounds, even at the supra-physiologic concentrations. So, the cytotoxicity of the extracts is probably not due to their phenolic content. This result was partially expected considering that P. brassicae butterfly extract, with no phenolic compound determined, seems to be one of the most toxic extracts (Figure 5).

When evaluated for their antioxidant potential in V79 cells subjected to $\mathrm{H}_{2} \mathrm{O}_{2}$ induced acute oxidative stress, the extracts failed to protect and even aggravated the deleterious effects of this oxidative agent. With the exception of $P$. brassicae excrements, the observed potentiation of $\mathrm{H}_{2} \mathrm{O}_{2}$-induced toxicity can be partly attributed to the toxicity of the extracts (Figure 5). However, these results do not agree with the antioxidant potential exhibited before by aqueous extracts of the same matrices in several non-cellular assays [6]. In that work P. brassicae materials and host kale aqueous extracts exhibited scavenging capacity against superoxide and nitric oxide radicals. The lack of correlation between the two models can be explained taking into account that some activities of the compounds may not be evaluated in chemical systems, or the concentrations required to scavenge pro-oxidant species may be deleterious to the cells [26]. A similar behavior was observed with B. oleracea var. costata, closely related to kale [15]. In cellular models the phenolic ring of polyphenols can be metabolized by peroxidase to form pro-oxidant phenoxyl radicals which, in some cases, are sufficiently reactive to cooxidize GSH or NADH, accompanied by extensive oxygen uptake and reactive oxygen species formation [4].

Phenolics are known for their protective activity against the deleterious effects of $\mathrm{H}_{2} \mathrm{O}_{2}[27,28]$. However, in this model, kaempferol-3-O-rutinoside, ferulic and sinapic acids, didn't prevent nor aggravate the toxicity induced by $\mathrm{H}_{2} \mathrm{O}_{2}$ in V79 cells (Figure 6). The extracts were characterized by the presence of complex molecules, highly glycosylated, some of them being also acylated and sulfated. These molecules possess higher molecular weight and are more polar than aglycones. Thus, they may not manage to pass the cell membrane at amounts sufficient to act as antioxidants. In addition, the contribution of unidentified compounds to the observed cytotoxicity and potentiation of $\mathrm{H}_{2} \mathrm{O}_{2}$-induced toxicity cannot be ignored.

Glutathione is the most abundant non-protein thiol in living organisms, playing a crucial role in intracellular protection against toxic compounds, such as oxidative agents [29]. Specifically, GSH is involved in cellular defense against $\mathrm{H}_{2} \mathrm{O}_{2}$. The extracts by themselves seem to affect to some extent GSH homeostasis, leading to an increase of oxidized glutathione and, consequently, to an increase of the toxic effect of $\mathrm{H}_{2} \mathrm{O}_{2}$ (Figures 5 and 7). On the contrary, kaempferol-3-O-rutinoside, sinapic or 
ferulic acids didn't significantly affect the $\mathrm{GSSG} / \mathrm{GSH}_{\mathrm{t}}$ ratio in V79 cells either with or without $\mathrm{H}_{2} \mathrm{O}_{2}$ treatment (Figure 9).

Thus, none of the tested extracts, as well as standard compounds, provided protection against deleterious $\mathrm{H}_{2} \mathrm{O}_{2}$ effects in V79 cells. The cytotoxic effect of $\mathrm{H}_{2} \mathrm{O}_{2}$ has been found to be catalyzed by metal ions, especially iron and copper, and it has been reported that metal chelators are effective in preventing such damage [30]. Previous studies in V79 cells showed that polyphenols having $o$-hydroxyl groups are effective in protecting against $\mathrm{H}_{2} \mathrm{O}_{2}$ induced cytotoxicity, whereas compounds lacking one of the $o$-hydroxyl groups were ineffective [20]. The main phenolics in the analyzed extracts lack the catechol group, an important feature for metal chelation, which may, at least partially, explain our results.

Considering kale methanolic extract, it should be highlighted the significant higher $\mathrm{GSH}_{\mathrm{t}}$ levels (over three times) found for the highest concentration tested (Figure 8). These results may suggest cells' attempt to increase their levels of antioxidants, in order to overcome the aggression to which they were submitted. Among the three phenolic compounds tested, only kaempferol-3-O-rutinoside lead to an increase of $\mathrm{GSH}_{\mathrm{t}}$ levels at the highest tested concentration (Figure 9). As so, flavonol derivatives seem to contribute for these results, once kale was clearly the richest matrix in terms of this kind of compounds (Figure 4 and Table 1). Flavonoids have already proved to induce $\gamma$-glutamylcysteine synthetase, the rate limiting enzyme involved in glutathione biosynthesis [29].

\section{Experimental}

\subsection{Reagents}

Ferulic and sinapic acids, quercetin-3-O-glucoside, kaempferol-3-O-rutinoside and isorhamnetin-3$O$-glucoside were from Extrasynthése (Genay, France). Reagents for cell culture were obtained from Invitrogen (Gibco, Grand Island, NY, USA): Dulbecco's modified Eagle's medium (4.5 g/L glucose, with l-glutamine and pyruvate; DMEM), phosphate-buffered saline (PBS), trypsin (2.5\%), penicillin $(5,000 \mathrm{U} / \mathrm{mL})$-streptomycin $(5,000 \mu \mathrm{g} / \mathrm{mL})$ and fetal bovine serum (FBS). Folin-Ciocalteu reagent, reduced glutathione (GSH), oxidized glutathione (GSSG), glutathione reductase (GR) (EC 1.6.4.2) and other reagents were reagent grade and obtained from Sigma, (St. Louis, MO, USA) and Merck (Darmstadt, Germany). Water was treated in a Milli-Q (Millipore, Bedford, MA, USA) water purification system.

\subsection{Samples}

Wild P. brassicae larvae were collected in Bragança (Northeast Portugal) and taken to the laboratory to complete their life cycle, including oviposition in kale (B. oleracea var. acephala) leaves. Identification was performed by José A. Pereira, Ph.D. (CIMO). Larvae fed with kale ad libitum were allowed to develop until the fourth instar and kept without food for $12 \mathrm{~h}$ before freezing. The excrements were also collected and frozen. Other larvae were allowed to reach the adult stage, being collected less than $24 \mathrm{~h}$ after eclosion. P. brassicae (larvae, excrements and butterflies) and kale leaves were freeze-dried. The dried material was powdered and kept in a desiccator in the dark until analysis. 
Voucher specimens were deposited at Laboratory of Pharmacognosy from the Faculty of Pharmacy of Porto University.

\subsection{Extract Preparation}

Each sample (ca. $2.7 \mathrm{~g}$ ) was thoroughly mixed with methanol $(3 \times 100 \mathrm{~mL}$, at $600 \mathrm{rpm}$, for $1 \mathrm{~h})$ and then filtered through a Büchner funnel. The extracts were concentrated to dryness under reduced pressure $\left(40{ }^{\circ} \mathrm{C}\right)$, and redissolved in ca. $50 \mathrm{~mL}$ acidic water $(\mathrm{pH} 2$ with $\mathrm{HCl})$. For phenolics purification, the obtained solution was passed through a C18 non-end-capped (NEC) column (50 $\mu \mathrm{m}$ particle size, $60 \AA$ porosity, $10 \mathrm{~g}$ of sorbent mass/70 $\mathrm{mL}$ of reservoir volume; Chromabond, Macherey-Nagel, Germany). The column was previously conditioned with $30 \mathrm{~mL}$ of methanol and $70 \mathrm{~mL}$ of acidic water. The phenolic fraction retained in the column was then eluted with methanol (ca. $50 \mathrm{~mL}$ ). The extract was evaporated to dryness under reduced pressure $\left(40{ }^{\circ} \mathrm{C}\right)$ and stored at $-20^{\circ} \mathrm{C}$ protected from light.

\subsection{HPLC-DAD Phenolic Compounds Analysis}

For HPLC-DAD analysis the dried extracts were dissolved in $2 \mathrm{~mL}$ of methanol and filtered through a $0.22 \mu \mathrm{m}$ size pore membrane. Analyses were performed as previously described [6], using a Gilson HPLC-DAD unit and a Spherisorb ODS2 $(25.0 \times 0.46 \mathrm{~cm} ; 5 \mu \mathrm{m}$ particle size $)$ column. Elution was developed with acetic acid $1 \%$ (A) and methanol (B), using the following gradient (1 mL/min): 0 min-10\% B, 30 min-40\% B, 35 min-60\% B, 37 min-80\% B, 50 min-94\% B. Detection was achieved with a Gilson diode array detector. Spectroscopic data from all peaks were accumulated in the range 240-400 nm, and chromatograms were recorded at $330 \mathrm{~nm}$. The different phenolic compounds were identified by comparing their chromatographic behavior and UV-vis spectra with authentic standards and with data previously obtained by our group, using the same analytical conditions [6]. In order to guarantee the identity of the peaks the samples previously characterized by LC-MS (references 6, 9 and 10), were newly injected and compared with the new ones.

Phenolic compounds quantification was achieved by the absorbance recorded in the chromatograms relative to external standards. Sinapic and ferulic acid derivatives were quantified as sinapic and ferulic acids, respectively. Since standards of several identified compounds were not commercially available, kaempferol, isorhamnetin and quercetin derivatives were quantified as kaempferol-3- $O$-rutinoside, isorhamentin-3-O-glucoside and quercetin-3-O-glucoside, respectively.

\subsection{Cell Culture and Treatments}

In order to study the antioxidant activity of the methanolic extracts of kale and $P$. brassicae materials, V79 hamster lung fibroblast line was used, following the method described before [31] with modifications. Cells were maintained and grown as a monolayer in culture plastic flasks $\left(75 \mathrm{~cm}^{2}\right)$. The culture medium was DMEM, containing 10\% heat-inactivated fetal bovine serum, $100 \mathrm{U} / \mathrm{mL}$ penicillin, $100 \mu \mathrm{g} / \mathrm{mL}$ streptomycin and $1 \%$ non-essential amino acids. Cells were kept in an incubator at $37{ }^{\circ} \mathrm{C}$ with a humidified atmosphere of $95 \%$ air and $5 \% \mathrm{CO}_{2}$. 
The dried methanolic extracts of kale and P. brassicae materials were dissolved and diluted in medium containing $0.1 \%(\mathrm{v} / \mathrm{v})$ dimethyl sulfoxide (DMSO). The final concentration of DMSO did not affect cellular viability.

To determine the effect of the extracts of kale and P. brassicae materials on V79 cells, viability and glutathione (total and oxidized) content were assessed $24 \mathrm{~h}$ after exposure. The potential protective effect against oxidative stress induced by $\mathrm{H}_{2} \mathrm{O}_{2}$ was also evaluated. For this purpose, in order to establish the $\mathrm{H}_{2} \mathrm{O}_{2}$ levels that resulted in $50 \%$ cell death, V79 cells were exposed to 37.5, 75.0 and $150 \mu \mathrm{M}$ (final concentration) $\mathrm{H}_{2} \mathrm{O}_{2}$, for different periods (30 and $60 \mathrm{~min}$ ). Attending to the results obtained (data not shown), $30 \mathrm{~min}$ exposure to $37.5 \mu \mathrm{M} \mathrm{H}_{2} \mathrm{O}_{2}$ was selected. So, cells were pre-treated for $24 \mathrm{~h}$ with the extracts and then exposed to $\mathrm{H}_{2} \mathrm{O}_{2}$ according to the selected conditions before determination of cellular viability and glutathione content.

\subsection{Cell Viability}

MTT was measured as described before by Sousa and collaborators [15]. Briefly, after cells exposure to extract, or extract plus $\mathrm{H}_{2} \mathrm{O}_{2}$, the medium was removed and the cells were incubated for $30 \mathrm{~min}$, at $37{ }^{\circ} \mathrm{C}$, with culture medium containing $0.5 \mathrm{mg} / \mathrm{mL}$ MTT. Afterwards, the solution was removed and formazan crystals were solubilized with $250 \mu \mathrm{L}$ DMSO. The resulting purple solution was measured spectrophotometrically at $570 \mathrm{~nm}$. Data are presented as the percentage of MTT reduction of treated cells relative to control, either with or without $\mathrm{H}_{2} \mathrm{O}_{2}$. Kaempferol-3-O-rutinoside and ferulic and sinapic acids were assayed in the same conditions of the extracts. Four independent assays were conducted, each one of them in quadruplicate.

\section{7. $\mathrm{GSH}_{t}$ and $G S S G$ Determination}

The cellular glutathione $\left(\mathrm{GSH}_{\mathrm{t}}\right)$ levels were determined by the 5,5'-dithiobis(2-nitrobenzoic acid) (DTNB)-GSSG reductase recycling assay after protein precipitation with perchloric acid, as described before [15]. Oxidized glutathione (GSSG) was determined after sample pre-treatment with 2-vinylpyridine. Four independent assays were performed.

\subsection{Measurement of Protein Content}

Protein content was measured using Lowry method with bovine serum albumin as standard, as previously described [32].

\subsection{Statistical Analysis}

Comparisons were performed by two-way analysis of variance (ANOVA), with the Bonferroni post hoc test, using GraphPad Prism 5 software.

\section{Conclusions}

This study is the first report on the cell effect of $P$. brassicae. Also the activity of its host plant, kale, was evaluated for the first time in V79 cells. The results showed no protective activity under acute $\mathrm{H}_{2} \mathrm{O}_{2}$ cellular insult, implying that polyphenol rich extracts are not always beneficial under 
pro-oxidant conditions. Despite the ability of kale extract to increase glutathione levels, one of the most important cellular defenses against oxidative stress, the cytotoxicity of $\mathrm{H}_{2} \mathrm{O}_{2}$ was aggravated by the extract, in this cellular model. Indeed, the antioxidant properties of kale and P. brassicae materials previously observed in non-cellular assays and the results obtained in the present biological assay lack correlation.

These results emphasize that the claimed antioxidant potential of extracts rich in phenolic compounds currently observed in cell free systems is not always confirmed in cellular models of induced oxidative stress. The results obtained also suggest that the industrial exploitation of kale or P. brassicae extracts as source of antioxidants needs care, as they may be especially harmful to health debilitated individuals.

\section{Acknowledgments}

The authors are grateful to Fundação para a Ciência e a Tecnologia (FCT) through grant no. PEst-C/EQB/LA0006/2011, to "Consolider Ingenio 2010 Project CSD2007-00063 FUN-C-FOOD" and to "Grupo de excelencia de la región de Murcia 04486/GERM/06". Fátima Fernandes is indebted to FCT for the grant (SFRH/BD/37963/2007).

\section{Conflict of Interest}

The authors declare no conflicts of interest.

\section{References and Notes}

1. Verhoeven, D.T.H.; Goldbohm, R.A.; Van Poppel, G.; Verhagen, H.; Van Den Brandt, P.A. Epidemiological studies on Brassica vegetables and cancer risk. Cancer Epidemiol. Biomark. Prev. 1996, 5, 733-748.

2. Podsedek, A. Natural antioxidants and antioxidant capacity of Brassica vegetables: A review. LWT-Food Sci. Technol. 2007, 40, 1-11.

3. Singh, M.; Arseneault, M.; Sanderson, T.; Murthy, V.; Ramassamy, C. Challenges for research on polyphenols from foods in Alzheimer's disease: Bioavailability, metabolism, and cellular and molecular mechanisms. J. Agric. Food Chem. 2008, 56, 4855-4873.

4. Galati, G.; Sabzevari, O.; Wilson, J.X.; O’Brien, P.J. Prooxidant activity and cellular effects of the phenoxyl radicals of dietary flavonoids and other polyphenolics. Toxicology 2002, 177, 91-104.

5. Cartea, M.E.; Velasco, P.; Obregón, S.; Padilla, G.; de Haro, A. Seasonal variation in glucosinolate content in Brassica oleracea crops grown in northwestern Spain. Phytochemistry 2008, 69, 403-410.

6. Ferreres, F.; Fernandes, F.; Oliveira, J.; Valentão, P.; Pereira, J.A.; Seabra, R.M.; Andrade, P.B. Metabolic profiling and biological capacity of Pieris brassicae fed with kale (Brassica oleracea L. var. acephala). Food Chem. Toxicol. 2009, 47, 1209-1220.

7. Vallejo, F.; Tomás-Barberán, F.A.; Ferreres, F. Characterisation of flavonols in broccoli (Brassica oleracea L. var. italica) by liquid chromatography-UV diode-array detection-electrospray ionisation mass spectrometry. J. Chromatogr. A 2004, 1054, 181-193. 
8. Ferreres, F.; Sousa, C.; Valentão, P.; Pereira, J.A.; Seabra, R.M.; Andrade, P.B. Tronchuda cabbage flavonoids uptake by Pieris brassicae. Phytochemistry 2007, 68, 361-367.

9. Ferreres, F.; Valentão, P.; Pereira, J.A.; Bento, A.; Noites, A.; Seabra, R.M.; Andrade, P.B. HPLC-DAD-MS/MS-ESI screening of phenolic compounds in Pieris brassicae L. reared on Brassica rapa var. rapa L. J. Agric. Food Chem. 2008, 56, 844-853.

10. Ferreres, F.; Fernandes, F.; Pereira, D.M.; Pereira, J.A.; Valentão, P.; Andrade, P.B. Phenolics metabolism in insects: Pieris brassicae-Brassica oleracea var. costata ecological duo. J. Agric. Food Chem. 2009, 57, 9035-9043.

11. Pereira, D.M.; Noites, A.; Valentão, P.; Ferreres, F.; Pereira, J.A.; Vale-Silva, L.; Pinto, E.; Andrade, P.B. Targeted metabolite analysis and biological activity of Pieris brassicae fed with Brassica rapa var. rapa. J. Agric. Food Chem. 2009, 57, 483-489.

12. Sousa, C.; Pereira, D.M.; Valentão, P.; Ferreres, F.; Pereira, J.A.; Seabra, R.M.; Andrade, P.B. Pieris brassicae inhibits xanthine oxidase. J. Agric. Food Chem. 2009, 57, 2288-2294.

13. Fernandez-Panchon, M.S.; Villano, D.; Troncoso, A.M.; Garcia-Parrilla, M.C. Antioxidant activity of phenolic compounds: from in vitro results to in vivo evidence. Crit. Rev. Food Sci. Nutr. 2008, 48, 649-671.

14. Lima, C.F.; Carvalho, F.; Fernandes, E.; Bastos, M.L.; Santos-Gomes, P.C.; Fernandes-Ferreira, M.; Pereira-Wilson, C. Evaluation of toxic/protective effects of the essential oil of Salvia officinalis on freshly isolated rat hepatocytes. Toxicol. In Vitro 2004, 18, 457-465.

15. Sousa, C.; Pontes, H.; Carmo, H.; Dinis-Oliveira, R.J.; Valentão, P.; Andrade, P.B.; Remião, F.; Bastos, M.L.; Carvalho, F. Water extracts of Brassica oleracea var. costata potentiate paraquat toxicity to rat hepatocytes in vitro. Toxicol. In Vitro 2009, 23, 1131-1138.

16. Talorete, T.P.N.; Bouaziz, M.; Sayadi, S.; Isoda, H. Influence of medium type and serum on MTT reduction by flavonoids in the absence of cells. Cytotechnology 2006, 52, 189-198.

17. Murray, J.I.; Whitfield, M.L.; Trinklein, N.D.; Myers, R.M.; Brown, P.O.; Botstein, D. Diverse and specific gene expression responses to stresses in cultured human cells. Mol. Biol. Cell 2004, $15,2361-2374$.

18. Ündeğer, Ü.; Başaran, A.; Degen, G.H.; Başaran, N. Antioxidant activities of major thyme ingredients and lack of (oxidative) DNA damage in V79 Chinese hamster lung fibroblast cells at low levels of carvacrol and thymol. Food Chem. Toxicol. 2009, 47, 2037-2043.

19. Choi, Y.-J.; Kang, J.-S.; Park, J.H.Y.; Lee, Y.-J.; Choi, J.-S.; Kang, Y.-H. Polyphenolic flavonoids differ in their antiapoptotic efficacy in hydrogen peroxide-treated human vascular endothelial cells. J. Nutr. 2003, 133, 985-991.

20. Nakayama, T. Suppression of hydroperoxide-induced cytotoxicity by polyphenols. Cancer Res. 1994, 54, 1991S-1993S.

21. Piao, M.J.; Kang, K.A.; Zhang, R.; Ko, D.O.; Wang, Z.H.; You, H.J.; Kim, H.S.; Kim, J.S.; Kang, S.S.; Hyun, J.W. Hyperoside prevents oxidative damage induced by hydrogen peroxide in lung fibroblast cells via an antioxidant effect. Biochim. Biophys. Acta 2008, 1780, 1448-1457.

22. Zou, Y.P.; Lu, Y.H.; Wei, D.Z. Protective effects of a flavonoid-rich extract of Hypericum perforatum L. against hydrogen peroxide-induced apoptosis in PC12 cells. Phytother. Res. 2010, 24, S6-S10. 
23. Halliwell, B. Reactive oxygen species and the central nervous system. J. Neurochem. 1992, 59, 1609-1623.

24. Scalbert, A.; Williamson, G. Dietary intake and bioavailability of polyphenols. J. Nutr. 2000, 130, 2073S-2085S.

25. Skibola, C.F.; Smith, M.T. Potential health impacts of excessive flavonoid intake. Free Radic. Biol. Med. 2000, 29, 375-383.

26. Liu, R.H.; Finley, J. Potential cell culture models for antioxidant research. J. Agric. Food Chem. 2005, 53, 4311-4314.

27. Aherne, S.A.; O'Brien, N.M. Lack of effect of the flavonoids, myricetin, quercetin, and rutin, on repair of $\mathrm{H}_{2} \mathrm{O}_{2}$-induced DNA single-strand breaks in Caco-2, Hep G2, and V79 cells. Nutr. Cancer 2000, 38, 106-115.

28. Qu, W.; Fan, L.; Kim, Y.C.; Ishikawa, S.; Iguchi-Ariga, S.M.; Pu, X.P.; Ariga, H. Kaempferol derivatives prevent oxidative stress-induced cell death in a DJ-1-dependent manner. J. Pharmacol. Sci. 2009, 110, 191-200.

29. Myhrstad, M.C.; Carlsen, H.; Nordström, O.; Blomhoff, R.; Moskaug, J.Ø. Flavonoids increase the intracellular glutathione level by transactivation of the gamma-glutamylcysteine synthetase catalytical subunit promoter. Free Radic. Biol. Med. 2002, 32, 386-393.

30. Jornot, L.; Petersen, H.; Junod, A.F. Hydrogen peroxide-induced DNA damage is independent of nuclear calcium but dependent on redox-active ions. Biochem. J. 1998, 335, 85-94.

31. Carmo, H.; Brulport, M.; Hermes, M.; Oesch, F.; de Boer, D.; Remião, F.; Carvalho, F.; Schön, M.R.; Krebsfaenger, N.; Doehmer, J.; et al. CYP2D6 increases toxicity of the designer drug 4-methylthioamphetamine (4-MTA). Toxicology 2007, 229, 236-244.

32. Lowry, O.H.; Rosebrough, N.J.; Farr, A.L.; Randall, R.J. Protein measurement with the Folin phenol reagent. J. Biol. Chem. 1951, 193, 265-275.

Sample Availability: Samples of B. oleracea var. acephala leaves and P. brassicae butterfly, larvae, and its excrements are available from the authors.

(C) 2012 by the authors; licensee MDPI, Basel, Switzerland. This article is an open access article distributed under the terms and conditions of the Creative Commons Attribution license (http://creativecommons.org/licenses/by/3.0/). 